\title{
Energizing Strategies for Student Personnel Professionals
}

\author{
Richard B. Barnes
}

\section{Introduction}

Dealing with the stress and demands of our profession can be very challenging, even exhausting. We may often feel overworked, underpaid, misunderstood, and underestimated in regards to our value and potential. It is our challenge to serve as student development educators through providing maximum service to our clientele while often having only very limited resources available.

Because of the demanding challenges that we as student personnel professionals have chosen, special consideration ought to be given to developing and maintaining a healthy and positive personal energy level. What follows is a collection of simple but useful suggestions which may be helpful when dealing with the many challenges of our profession. These suggestions emphasize proactivity. To loosely paraphrase an old cliche, "An ounce of pro-action is worth a pound of reaction."

\section{General Strategies}

Assess Strengths and Limitations

- Solicit feedback from appropriate colleagues

- Make lists of personal and professional strengths and limitations

- Use testing inventories

- Have subordinates evaluate your performance

\section{Develop and Implement Goal Setting Strategies}

- Focus on specifics and objectives

- Use contracts

- Solicit support from colleagues

- Set deadlines

\section{Specific Strategies}

Critique and Develop Communication Skills

- Assess and develop assertiveness skills

- Use campus political maneuvering positively

- Say "please" and "thank you" to colleagues and subordinates

- Present a program or workshop at a conference 


\section{Utilize Planning Strategies}

- Outline and review daily, weekly, and semester tasks

- Set priorities

- Develop time management techniques that work for you

- Ask yourself: "What is the best use of my time right now?"

\section{Develop and Use a Support Network}

- Continuously clarify expectations between yourself, co-workers, and supervisors

- Develop a personal list of consultants

- Utilize support and advice from colleagues at other institutions

- Develop and maintain a resource file

\section{Review Your Sense of Purpose}

- Review personal and professional roles-how do they fit in with each other?

- Occasionally update your resume

- Review the last several years-are you headed in a direction that is agreeable with you?

\section{Develop and Maintain a Sense of Humor and Optimism}

— Find ways to brighten up your work setting

- Be cautious of sarcastic remarks - they tend to be very de-energizing

- Learn to laugh at yourself

— Verbally point out positive behavior to co-workers

\section{Develop and Maintain Your Physical Dimension}

- Take an active role in your physical health-choose a proper diet and exercise regularly

- Listen to and appreciate your body needs

- Get an adequate amount of rest

\section{Develop and Maintain Your Emotional Dimension}

- Make and take time for yourself

- Share your feelings with appropriate others

- Accept your feelings without guilt

- Establish a personal identity outside your work setting

- Accept your flaws

\section{Develop Relaxation and Recreational Activities}

- Take time within each day to relax

- Become an "enthusiast" of some form of recreation or hobby

- Realize the value and importance of "playing"

- Learn relaxation techniques that work for you 


\section{Accept Limitations}

- There is never enough time

- Not everybody cares

- There is not enough money

- You only have a finite amount of personal energy-use it well

- We all make mistakes and will continue to do so

\section{Summary}

It should be noted that when we operate from a purely reactive position this may often result in feelings of frustration and stagnation due to a sense of a lack of control in our work setting. It is important to realize that we may not have the influence to change and improve everything we would like. What is essential is that we focus on things we can change. We need to remind ourselves that attempts to change and improve are rarely met with instant, complete success. We must not become discouraged with occasional setbacks. Goals need to be continuously evaluated and reset. By taking a proactive approach to developing and maintaining personal energy, we enable ourselves to take charge of our work, our attitudes, our lives. 